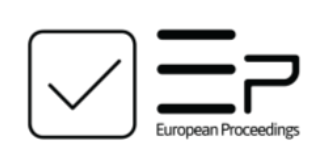

European Proceedings of

International Conference on Education \&

Educational Psychology

EPICEEPSY

www.europeanproceedings.com

e-ISSN: 2672-8141

DOI: $10.15405 /$ epiceepsy.21101.7

ICEEPSY 2021

$12^{\text {th }}$ International Conference on Education \& Educational Psychology

\title{
SUICIDAL BEHAVIOR AT SCHOOL FROM TEACHERS' PERSPECTIVE
}

\author{
Marie Herynková (a)*, Kateřina Drašnarová (b), Karolína Očenášková (b), \\ Alena Perglerová (b), Silvie Urbanová (b) \\ *Corresponding author \\ (a) Faculty of Education, University of Hradec Králové, Rokitanského 62, Hradec Králové, Czech Republic, \\ marie.herynkova@uhk.cz \\ (b) Faculty of Education, University of Hradec Králové, Hradec Králové, Czech Republic
}

\begin{abstract}
Suicide is one of the main causes of death among adolescents in Europe. It is therefore important to consider possible warning signs of suicidal behaviour. Important people in the lives of children and adolescents are teachers who may notice the above-mentioned signals. The purpose of the current study is to analyse the experience of teachers with the suicidal behaviour of pupils in primary and secondary schools. We were interested in the manifestations of pupils' suicidal behaviour at school and the ways teachers react to it. The recruited teachers completed an online self-designed questionnaire composed of quantitative and qualitative questions. The research group consisted of primary and secondary school teachers $(\mathrm{N}=52)$. The results of the research indicated the different experiences of primary and secondary school teachers with the suicidal behaviour of pupils. Regarding the forms of suicidal behaviour, teachers most often encounter pupils' selfharm (61.5\% of teachers), suicidal ideations and suicide speeches (46.2\%), as well as suicide attempts (23.1\%). $15.4 \%$ of teachers have already experienced a completed pupil suicide. Teachers' reactions to a pupil's suicidal behaviour are most often as follows: an individual interview with the pupil $(43.2 \%$ of teachers), informing parents $(36.4 \%)$, consulting with an expert on how to react $(23.9 \%)$ or ignoring and not resolving the situation $(11,4 \%)$.
\end{abstract}

2672-8141 @ 2021 Published by European Publisher.

Keywords: Suicidal behavior, pupils, teachers 


\section{Introduction}

In addition to completed suicide, suicidal behaviour includes suicide attempts and symptoms indicative of suicidal thoughts and intentions. The child's age plays an important role in suicidal behaviour. Suicidal behaviour in children under 14 is less common compared to adolescence, when its incidence increases significantly. It is reported that suicidal behaviour in adolescence is the second leading cause of death (Říčan \& Krejčířová, 2006). The significance and prevalence of suicidal behaviour are also confirmed by a European study from 2007, which dealt, among other things, with suicidal ideations and attempts among adolescents aged 15-16 from 17 European countries (45,806 students participated, the Czech Republic was not involved in the research). The lifetime prevalence of a suicide attempt was $10.5 \%$ (fluctuating between 4.1 and $23.5 \%$ across countries), whereas it was almost twice as common in girls compared to boys. Repetition of suicide attempts was high: half of the students who reported any suicide attempt reported more than one (Kokkevi et al., 2012). Suicide is not just a life-threatening public health problem, but it has serious psychological effects on pupils' parents, friends, classmates and teachers. The most recent suicide of a student had (some or great) impact on the personal life of $76 \%$ of teachers and on the professional life of $85.7 \%$ (Kolves et al., 2017).

Suicidal behaviour is associated with self-harm. Although self-harm is not classified as suicidal behaviour, they have common characteristics such as suicidal ideations and fantasies, depressions, feelings of hopelessness. However, in self-harm, the primary goal is not to die. It should be noted though that selfharm and suicidal behaviour are interrelated, as more than half of those who self-harm will perform at least one suicidal attempt (Koutek \& Kocourková, 2003). Morgan et al. (2017) published an extensive population study investigating the teenagers in the UK aged 10-19, who self-harmed between the years 2001 and 2014. They found out that half of the teenagers who died in suicide had committed self-harm in the past. For this reason, the national suicide prevention strategy seeks to reduce the incidence of self-harm among adolescents. Research suggests that self-harm, along with self-harming and suicidal ideations, affect at least $10 \%$ of the adolescent population. Thus, self-harm belongs among the riskiest factors for suicidal behaviour (Hoferková \& Jašková, 2018).

Teachers have great opportunities to assess the risk factors in children and adolescents and so significantly contribute to the prevention of suicidal behaviour (King et al., 1999). But are teachers trained to detect these warning signs? Australian research concludes that teachers as a professional group are illinformed in particular about risk factors for suicidal behaviour (Scoullar \& Smith, 2002). Teachers in South Africa are in a similar situation (Shilubane et al., 2015). In the survey of US high school teachers, $78 \%$ of them stated they knew the adolescent who attempted / completed suicide (Westefeld et al., 2007). When asked how they would react, $45.9 \%$ of the respondents reported that they would do nothing, $67.2 \%$ of respondents indicated that they would contact the school counsellor, $29.5 \%$ of respondents would contact parents, $25.4 \%$ of respondents would contact school administrators, and $19.7 \%$ of respondents would discuss the issue with the student. 


\section{Problem Statement}

Children and adolescents can often get into a situation that is beyond their ability to cope. They get into situations over which they have no control and have not yet developed coping strategies to find the help they need (Juhnke et al., 2010). In that case, there is a risk of suicidal behaviour. Therefore, our interest subsequently focused on the following questions: To what extent do teachers notice suicidal behaviour? What are teachers' experiences with pupils' suicidal behaviour? How do teachers react to suicidal behaviour?

The reason for the subject of research is the few empirical studies dealing with the suicidal behaviour of pupils from the perspective of teachers in the Czech Republic.

\section{Purpose of the Study}

The study aim is to analyse the experience of teachers with the suicidal behaviour of pupils in primary and secondary schools.

We operationalized these goals into the following research questions:

Question 1: In what form do teachers encounter pupils' suicide behaviour?

Question 2: How teachers react to pupils' suicidal behaviour?

Question 3: What is the correlation between the number of pupils with suicidal behaviour that teachers experienced during their practice and selected variables (age, length of practice, job satisfaction, community size, the extent to which they feel to be accepted by school management, pupils' parents, colleagues, and pupils)?

\section{Research Methods}

\subsection{Instruments}

As a research tool was selected an electronic questionnaire of our own design. The questionnaire contained 24 questions (16 quantitative questions, 8 qualitative questions). The results presented in this paper relate to a) 11 quantitative questions (detecting gender, age, length of practice, size of the municipality, type of school, job satisfaction, the extent to which teachers feel accepted by the school management, pupils' parents, colleagues and pupils, and also the number of pupils with suicidal behaviour) and b) 2 qualitative questions (asking about the forms of pupils' suicidal behaviour that the teachers encountered during their practice and how they reacted to the pupils' suicidal behaviour).

\subsection{Procedure and research sample}

The authors present an empirical study with a mixed research design, the data were provided by a one-time questionnaire survey. The questionnaire was distributed through e-mail addresses and Facebook groups for teachers. The research group consisted of 52 people aged 25 to 66 years $(\mathrm{M}=42,35$; $\mathrm{SD}=$ $10,57)$, who currently work as teachers with a length of practice of 1 to 42 years $(M=16,54 ; S D=11,14)$. The sample included 15 teachers working in primary school $(28,8 \%), 24$ teachers working in a lower- 
secondary school $(46,2 \%), 13$ teachers working at secondary schools $(25,0 \%)$. In terms of gender, there were 51 women $(98,1 \%)$ and 1 man $(1,9 \%)$.

\section{Findings}

\subsection{Forms of suicidal behaviour}

Teachers' answers to the question of what forms of suicidal behaviour they encountered in their work at school were processed qualitatively using the method of constant comparison. 26 respondents $(50 \%)$ answered the question, while the answers of some respondents were included in multiple categories. Subsequently, frequency analysis was used to indicate the frequency of respondents' answers to the individual categories created. The following five categories emerged:

1. Self-harm (61.5\%)

2. Suicidal ideations and speeches $(46.2 \%)$

3. Suicidal attempts $(23.1 \%)$

4. Completed suicide (15.4\%)

5. Suicidal creation in the form of writing or drawing $(11.5 \%)$

\subsection{Teachers 'reactions to pupils' suicidal behavior}

The question of how teachers reacted to the findings regarding the pupil's suicidal behaviour was answered by 44 teachers $(84.6 \%)$. The answers of some respondents were included in several categories. We processed the answers qualitatively using the method of constant comparison. Subsequently, frequency analysis was used to indicate the frequency of respondents' answers to the individual categories created. The following eight categories emerged:

1. Interview (43.2\%) - individual interview with the student

2. Informing parents (36.4\%)

3. Get advice on how to deal with a pupil $(23.9 \%)$ - a consultation with a psychologist was most often mentioned

4. Not to solve it, ignore it (11.4\%)

5. Report to the school staff (11.4\%) - in the answers respondents mentioned that they had reported it to the class teacher, school psychologist, prevention methodologist or school management

6. Recommendation to seek professional help (9.1\%) - a visit to the Pedagogical and Psychological Counselling Centre, a crisis hotline, a psychologist, or a psychiatrist was mostly recommended 7. Increased attention to the pupil (9.1\%) - pay more attention to the pupil, watch him/her closely

8. Talk about it with the whole class $(4.5 \%)$ - in the presence of a pupil with suicidal behaviour

\subsection{Correlation between the number of pupils with suicidal behaviour and selected variables}

In response to the question of how many pupils with suicidal behaviour the teachers have encountered during their practice, they differed quite considerably. 51 teachers $(98.1 \%)$ answered the question. On average, they met 4.75 pupils with suicidal behaviour $(\mathrm{SD}=13.89)$ during their practice. The 
average length of practice of our research group was 16.64 years. Using Pearson's correlation coefficient, we calculated whether there was a correlation between the number of pupils with suicidal behaviour that teachers encountered and the age of teachers, length of practice, job satisfaction, type of school (1 st grade, 2nd grade of primary school, secondary school), community size, and how they feel to be accepted by the school management, parents, colleagues, pupils. Only one statistically significant correlation was found, namely between the number of pupils with suicidal behaviour and the teachers' evaluation of how they are perceived and accepted by the parents $(r=-0.670, p<0.001)$. The more teachers feel to be accepted by the parents, the fewer pupils with suicidal behaviour they have encountered during their teaching practice.

\section{Discussion}

In this subchapter, we deal with the interpretation of the obtained results concerning the research questions and possible limits of the research.

We found the answer to the first research question asking about the forms of suicidal behaviour that teachers encounter in pupils. Most teachers (61.5\%) experienced self-harm in pupils, $46.2 \%$ of teachers encountered suicidal ideation, $23.1 \%$ suicidal attempts, $15.4 \%$ completed suicide and $11.5 \%$ suicidal creation in the form of text or artwork. Compared to American research respondents (Westefeld et al., 2007), our research group less frequently encounters suicidal attempts or completed suicide among pupils. There are several possible explanations: e.g. children and adolescents in the Czech Republic have fewer suicide attempts or completed suicides, or they less often entrust to their teachers, or our teachers pay less attention to suicidal behaviour symptoms comparing to the American teachers and pupils. We recommend further verifying the above mentioned possible explanations with more in-depth research.

The second research question dealt with teachers 'reactions to pupils' suicidal behaviour. The teachers mentioned several ways of reacting, which we summarized into eight categories. Most teachers (43.2\%) talked to the pupil in person, $36.4 \%$ of teachers informed the parents concerned, $23.9 \%$ of teachers took advice on how to act, and $11.4 \%$ of teachers did not react and did not solve it. Pupils' suicidal behaviour is a challenging topic for many teachers, with several concerns about how to react so as not to make matters even worse; what words to choose; the fear that if the teacher asks too many questions, he/she may move the pupil towards suicide; fear of losing the pupil's confidence when informing his/her parents and school staff about his/her behaviour; general concerns about available resources for referrals. Some myths are also associated with suicidal behaviour. To mention one of the most damaging - the myth that those who talk about suicide, will not commit it. This myth may be the reason why some teachers do not respond to obvious signs of suicidal behaviour. Compared to the aforementioned US research (Westefeld et al., 2007), in which $45.9 \%$ of teachers stated that they would do nothing. It seems that teachers in our research group choose more proactive strategies.

A 2007 survey of adolescents from 17 European countries showed that, on average, 10.5\% of adolescents committed at least one suicide attempt. This is a very alarming number that parents and teachers are probably unaware of. This is confirmed by the findings of our research, as teachers report a very low number of suicidal pupils they have encountered during their practice (on average, they met 4.75 pupils with suicidal behaviour per an average length of practice of 16.64 years). Apparently, they are unaware of how many pupils are struggling with suicidal behaviour. In our research group, no correlation was found 
between the reported number of pupils with suicidal behaviour and the age of teachers, the length of practice, the size of the municipality, and job satisfaction. A strong negative correlation was detected between the extent to which teachers feel to be accepted by their pupils' parents and the number of pupils with suicidal behaviour. We expected a fairly positive correlation between these two variables since it seems logical that the acceptance of the teacher by the parents will lead to improved relationships, which will, in turn, increase parents' courage to confine in the suicidal behaviour of their children. On the other hand, a low level of acceptance by pupils' parents may be an indicator of problems on the part of pupils' families, and thus there is a greater risk of pupils' suicidal behaviour. In the research of risk factors of childhood and adolescent suicidality, the most common motivations were just family problems (Kocourková \& Koutek, 2006).

The limits of our study include the lack of representativeness of the research group. Another limit is the low number of respondents, with only one man in the research group.

\section{Conclusion}

Due to the low number of respondents, this study has limited generalizability of results. Nevertheless, the finding that teachers notice a relatively low number of pupils with suicidal behaviour compared to the estimated actual number deserves further investigation. Further research is needed both, to determine how the identification of pupils with suicidal behaviour could be improved, and how to improve teachers' intervention skills in such situations. Study findings reinforce the importance of raising awareness of pupils' suicidal behaviour, checking in about risk for suicide and training teachers in how they should respond to pupils' suicidal behaviour. It is noteworthy that due to the time spent with children and adolescents, teachers are in a strategic position within the school setting and act as providers of the prevention of suicidal behaviour through the promotion of mental health in pupils at risk of suicidal behaviour.

\section{Acknowledgments}

This paper was supported by the Specific Research of the Faculty of Education, the University of Hradec Kralové 2021, No: 2112, entitled: Suicidal behaviour of pupils from the perspective of teachers and school psychologists.

\section{References}

Hoferková, M. S., \& Jašková, B. M. (2018). Sebepoškozování v zahraničních výzkumech jako podnět pro prevenci v českém školním prostředí [Self-harm in foreign research as an incentive for prevention in the Czech school enviroment]. Acta sociopathologica, 5, 91-101.

Juhnke, G. A., Granello, P. F., \& Granello, D. H. (2010). Suicide, self-injury, and violence in the schools: Assessment, prevention, and intervention strategies. John Wiley \& Sons. https://doi.org/10.1002/9781118269725

King, K. A., Price, J. H., Telljohann, S. K., \& Wahl, J. (1999). High school health teachers' perceived selfefficacy in identifying students at risk for suicide. Journal of School Health, 69, 202-207. https://doi.org/10.1111/j.1746-1561.1999.tb06386.x 
Kocourková, J., \& Koutek, J. (2006). Rizikové faktory dětské a adolescentní suicidality [Risk factors for childhood and adolescent suicidality]. Česká a slovenská psychiatrie, 8, 431-435.

Kokkevi, A., Rotsika, V., Arapaki, A., \& Richardson, C. (2012). Adolescents' self-reported suicide attempts, self-harm thoughts and their correlates across 17 European countries. Journal of Child Psychology and Psychiatry, 53(4), 381-389. https://doi.org/10.1111/j.1469-7610.2011.02457.x

Kolves, K., Ross, V., Hawgood, J., Spence, S. H., \& De Leo, D. (2017). The impact of a student's suicide: Teachers' perspectives. Journal of affective disorders, 207, 276-281. https://doi.org/10.1016/j.jad.2016.09.058

Koutek, J., \& Kocourková, J. (2003). Sebevražedné chování [Suicidal behavior]. Portál.

Morgan, C., Webb, R. T., Carr, M. J., Kontopantelis, E., Green, J., Chew-Graham, C. A., Kapur, N., \& Ashcroft, D. M. (2017). Incidence, clinical management, and mortality risk following self harm among children and adolescents: cohort study in primary care. BMJ (Clinical research ed.), 359, j4351. https://doi.org/10.1136/bmj.j4351

Říčan, P., \& Krejčířová, D. (2006). Dětská klinická psychologie [Child clinical psychology]. Grada.

Scoullar, B. A., \& Smith, D. I. (2002). Prevention of youth suicide: How well informed are the potential gatekeepers of adolescents in distress? Suicide and Life Threatening Behavior, 32, 67-79. https://doi.org/10.1521/suli.32.1.67.22182

Shilubane, H. N., Bos, A. E., Ruiter, R. A., van den Borne, B., \& Reddy, P. S. (2015). High school suicide in South Africa: teachers' knowledge, views and training needs. BMC public health, 15(1), 1-8. https://doi.org/10.1186/s12889-015-1599-3

Westefeld, J. S., Jenks Kettmann, J. D., Lovmo, C., \& Hey, C. (2007). High school suicide: Knowledge and opinions of teachers. Journal of Loss and Trauma,12(1), 33-44. https://doi.org/10.1080/15325020600757839 